\title{
University Selection Processes and Market Size: An Experimental Study
}

\author{
Ooi Tze Wei ${ }^{\mathrm{a}} \& \mathrm{Ch}^{\prime}$ ng Kean-Siang ${ }^{\mathrm{b}}$
}

\begin{abstract}
The administrator of a university selection process is often faced with allocation problems such as identifying the most talented candidates to be placed into the most sought-after university/course. This occurs because too many applicants are competing for a limited number of seats and the difficulty in identifying the qualified and interested candidate to attend the course, makes the selection process very tedious and slow. Although the selection process plays a role as a clearinghouse in allocation, the market congestion that occurred due to a large number of applications renders the process inefficient. The paper begins with the aim of studying three matching mechanisms; the Immediate Acceptance Mechanism (IAM), Deferred Acceptance Mechanism (DAM) and Efficient Transfer Mechanism (ETM), in terms of their truth-telling and stability properties in two market sizes. The parameter market size represented market congestion (i.e. a small market) and no market congestion (i.e. a large market). We find the Immediate Acceptance Mechanism lost to Deferred Acceptance and Efficient Transfer Mechanisms in terms of allocation and truth-telling; candidates in Immediate Acceptance Mechanism misreported their true preferences more to gain entry, which also rendered the mechanism less stable compared to the other two. A selection process should promote fairness in evaluation to encourage truth-telling which was found to be positively correlated with stability in allocation.
\end{abstract}

Keywords: University selection process; Matching mechanism; Stability; Truthtelling; Market size

JEL Classification: D47, D61, C92

\section{Introduction}

A university selection process, involves matching the much sought-after talents with universities/courses to which a student aspires. The selection process plays an important role as a clearinghouse to ensure all individual

a Economics Department, School of Social Sciences, Universiti Sains Malaysia, Penang, Malaysia.Email:ooiwei@gmail.com

b Corresponding author. Economics Department, School of Social Sciences, Universiti Sains Malaysia, Penang, Malaysia.Email:cks@usm.my 
applications are evaluated fairly and are allocated to the most suitable university based on qualifications (McKinney, Niederle \& Roth, 2005; Roth \& Sönmez, 2005). However, the process is not so straightforward. When all the applications and university choices made by the applicants are not evaluated, it will cause the clearinghouse to lose its usefulness. This happens when too many applications are received for a university/ course. Administrators are bogged down by the decision to choose the most qualified students and who will attend if chosen. Since the acceptance decision relies on a signal from the students not only as to how good they are academically but also on how interested they are, students have the incentive to misrepresent their true preferences through the ranking of universities/courses to gain entry. The present paper intends to study different university selection processes in different market sizes. We intend to study the possibility of the misreporting of preferences and the welfare of the university and student under each matching mechanism.

A successful market is that which brings together many participants who want to transact in one place, so they can search for the best deals. Having a thick market ensures all offers are evaluated. In the theory of Welfare Economics, private markets achieve allocation efficiency in which social welfare is maximised, when price plays a vital role in allocating scarce resources, provided two conditions are met - zero transaction costs and a clear assignment of property rights given to any one of the competing parties involved (Coase, 1960). However, in school or university matching markets, the allocation is not determined by price but by the underlying matching mechanism (Abdulkadiroğlu \& Sönmez, 2003; Ergin \& Sönmez, 2006; Haeringer \& Klijn, 2009; Kojima \& Unver, 2010). In a thick market such as in the university entry selection process, each application has to be evaluated individually. Given the wide range of options (i.e. university choices) available to the applicants and a large number of candidates applying for university each year, the evaluation process becomes very overwhelming and tedious for administrators. The sheer number of applications compounded by the university choices one can submit in the application form creates massive congestion in the university selection market each year, in which not all applications will be fairly evaluated. Ensuring that all applicants are evaluated and compared fairly - that the evaluation is fast enough so that those who are not successful can be considered for other universities and 
those who are chosen will register to attend to ensure no seats are wasted is not an easy task.

To overcome the allocation problems, several matching mechanisms have been introduced. The present paper focuses on three of the most widely studied mechanisms: the Immediate Acceptance Mechanism (IAM), Deferred Acceptance Mechanism (DAM) and Efficient Transfer Mechanism (ETM).

IAM refers to a matching mechanism that matches applicants with a school or university based on applicants' submitted priority list. It creates a large incentive for candidates to misreport their preference by ranking a school or university as the first choice to gain entry. Another implication of the mechanism is that it often leads to unstable matching, where a student is not assigned to a school they preferred while a student with a lower priority than them is admitted to the school (Abdulkadiroğlu \& Sönmez, 2003; Coles et al., 2010; Kojima \& Unver, 2010). Unstable matching happens because the system always prioritises students who highly rank the school, instead of allocating the students to a school based on the school priority list. In the United States, the Boston Mechanism (or IAM) was used to assign children to district schools until the Boston School Committee voted to replace the mechanism with the DAM in July 2005 following evidence that showed the welfare of parents who truthfully reported their preferences were adversely affected by the parents who strategised their preferences (Abdulkadiroglu, Pathak, Roth \& Sonmez, 2006).

Another matching mechanism DAM does not prioritise as much on ranking as IAM. Instead, the mechanism pools all qualified candidates into one place and compares their qualifications before accepting them. Compared with IAM, DAM does not accept a candidate immediately, but tentatively places these candidates in the pool and compares them with other qualified candidates. It has been reported as strategy-proof because telling the truth is the dominant strategy for each student (Alcalde \& Barberà, 1994) and the matching is stable (Dubins \& Freedman, 1981; Roth, 1982a; Willian \& Milgrom, 2005).

Another strategy-proof matching mechanism called the ETM, focuses on the welfare of students when there is a huge number of applicants in the pool (Roth, 1982b). The system pairs the top preferences of a university with the top preferences of students and swaps their assignments when there is a chance to improve the candidates' welfare without harming any party. 
Therefore, it reduces the need for students to misrepresent their choices in the preference list. (The detail allocation of each matching mechanism will be explained in Section 2).

Revealing true preferences in the application form is important for the administrator to match the most prestigious university with the most qualified student with a high interest to study there. Several experimental studies proved that preference manipulation often leads to misallocation or instability (Chen, Jiang, Kesten, Robin \& Zhu, 2018; Chen \& Kesten, 2017; Pais, Pintér \& Veszteg, 2011). The present paper intends to study the truth-telling and stability properties of the three matching mechanisms. The properties are tested in the context of a highly congested market (i.e. small market size) or not congested market (i.e. large market size). We vary the number of available seats with a small number of seats in small market size and a larger number of seats in a large market size.

While there have been many past studies on the effect of market size on truth-telling, the investigations were limited to one specific matching mechanism and did not compare the performance across all three mechanisms. Among the papers, Azevedo and Budish (2018) and Kojima and Pathak (2009) found that the incentive for subjects to misreport their preference in the IAM remained unchanged from small to large market size. On the other hand, Chen et al. (2018) experimentally showed that the proportion of truth-telling was higher in 4 subjects per match than 40 subjects per match in IAM, but the opposite result was obtained in DAM.

In terms of market size effect on matching stability, Crawford (1991) showed that adding more agents to one side of the one-to-one matching market made the agent on the other side only slightly better off, but also slightly worsened the side that had more agents, implying that stable matching was hard to form in a large market. On the contrary, large sets of unique stable matchings were obtained in the many-to-one matching market when the number of schools were held constant and the number of students increased drastically (Azevedo \& Leshno, 2016). Similar results also obtained in the one-to-one matching market (Immorlica \& Mahdian, 2005) the proportion of stable matchings between colleges and students grew as the market size became larger. No study has directly investigated the performance of the three matching mechanisms based on stability and truth-telling in different market sizes and the relation between truth-telling and stability in allocation, the present paper attempts to fill the gap. 
The paper is organised as follows; section two focuses on the theoretical framework. Each matching mechanism will be explained in detail in this section, as will the properties of truth-telling and market stability and the hypotheses of the study. Section three explains the experimental design. Section four reports the results and section five discusses the findings and implications of the study.

\section{Theoretical Framework}

We use the school or college matching mechanism framework to investigate three matching mechanisms under two different market sizes. The selection process in each matching mechanism is explained as follows:

\subsection{Immediate Acceptance Mechanism (IAM)}

The IAM is a non-strategy proof mechanism because a subject can improve their welfare through preference manipulation (Abdulkadiroğlu, Che \& Yasuda, 2011; Miralles, 2009; Troyan, 2012) . The selection process gives higher priority to the ranking of universities listed by the students, instead of the ranking of students predetermined by the universities. Thus, it creates large incentives for subjects to misrepresent their true preferences to gain admission. The complete mechanism is explained in the following stages.

In stage 1, the mechanism assigns the university to students who have listed it as their first choice and have fulfilled the minimum entry point set by the university until the capacity is filled.

In stage 2, the second choice of the students who get rejected in stage 1 is assigned to them until the capacity is filled if their result has fulfilled the minimum entry point set by the university. The same procedure is applied to the following stages until each student is given a seat, or the capacity of each university is exhausted.

\subsection{Deferred Acceptance Mechanism (DAM)}

The DAM is a strategy proof mechanism as no subject can improve their welfare (i.e. having a better assignment) by misrepresenting their true preference because telling the truth is the dominant strategy to gain admission (Abdulkadiroğlu \& Sönmez, 2003; Gale \& Shapley, 1962). The 
system tentatively accepts all qualified subjects in accordance with the ranking of universities they listed in the application form. The selection process then evaluates their qualification and accepts them based on the priority list of each university. In such a situation, subjects have a large incentive to tell the truth about the ranking of their preferred universities when submitting the application form to the clearing house. The complete mechanism is explained in the following stages.

In stage 1, the mechanism rejects students with a lower cumulative grade point average (CGPA) who have ranked the university as their first choice and keeps the students with a higher CGPA who have ranked the university as their first choice on hold until the university capacity is filled.

In stage 2, the mechanism compares the students who have been retained in stage 1 with other students who have listed the university as their second choice. Students with lower CGPA will be rejected and students with higher CGPA will be retained until the university capacity is filled.

In stage 3, students who had been retained in stage 2 will be compared with other students who rank the university as their third choice. Again, students who have been retained in stage 2 will be replaced by any student in stage 3 whose achievement is better. The same procedure applied to the following stages until each student is given a seat or the capacity of each university is exhausted.

\subsection{Efficient Transfer Mechanism (ETM)}

The ETM is another direct strategy proof mechanism because the system always looks to maximise the welfare of students through swapping assignments whenever there is a chance to improve student $X$ 's welfare without harming student Y's welfare or to improve both parities' welfare at the same time (Abdulkadiroglu \& Sönmez, 2003; Abdulkadiroğlu \& Sönmez, 1999). Swapping assignments are more likely to occur if both universities and students have a long chain of different choices and the population in the market is large (see, Abdulkadiroglu \& Sönmez, 2003). The complete mechanism is explained in the following stages.

In stage 1, the mechanism points each student who scores highest to their favorite university and points each university to its favorite student until the capacity of each university is exhausted, forming at least one cycle. In the cycle, the student is matched with a university. The assignment is then 
finalised, the student and the university are removed from the system.

In stage 2, the mechanism points each unmatched student who has the highest achievement to their favorite remaining university and points each remaining university to their favorite unmatched student until the university's capacity was exhausted. One cycle was formed at least. The assignment is then finalised, the student and the university are removed from the system. The mechanism continues in the same fashion for the following stages until each student is given a seat or the capacity of each university is exhausted.

The present paper tests the truth-telling and stability properties of each matching mechanism with two different market sizes; small and large markets.

\subsection{Truth-telling property}

Truth-telling refers to students reporting their true University preference in their applications. A student should report the best preference as the first choice and worst preference as the last choice. Any reporting other than that is referred to as manipulating preference, for example, listing second-best university as the first choice to gain entry. When a matching mechanism promotes fairness in matching, it eradicates the need to manipulate the choice list to game the system (Abdulkadiroğlu \& Sönmez, 2003). By removing the need for gaming, the system becomes more strategy-proof, fair competition among the students is promoted and therefore, candidates are convinced that their most preferred choices are always considered by the system without assigning a course to the other candidate with lower priority (Gale \& Shapley, 1962). Ultimately, a larger proportion of truthfully reported choices by candidates will have prevailed (Abdulkadiroğlu \& Sönmez, 2003; Kojima \& Unver, 2010). In this present study, we intend to find a system that is more strategy-proof to ensure the welfare of every student is taken care of and fairness is promoted.

\subsection{Matching stability}

Stable matching guarantees fairness in matching and ensures the welfare of university and student (Bodine-Baron, Lee, Chong, Hassibi \& Wierman, 2011; Hakimov \& Kübler, 2019). A matching is said to be stable when there is no blocking student-university pair (Balinski \& Sönmez, 1999; 
Calsamiglia, Haeringer \& Klijn, 2010; Pathak, 2011). A block (i; s) happens when (a) student " $i$ " prefer university "s" to their current assignment and (b) student " $j$ " with lower priority than student " $i$ " is assigned to university "s" (in other words, university "s" prefers student "i" over student " $j$ "). The blocking student-university pair gives rise to justified envy: the situation in which student "i" prefers university "s" to their assignment and they have higher priority than student " $j$ ", but student " $j$ " is assigned a seat at university "s". For illustrative purposes, there are three students $\left(s_{1}, s_{2}, s_{3}\right)$ and three universities $\left(U_{a}, U_{b}, U_{c}\right)$ with one seat available in each university. The priorities of the schools and the preference of the students are as follows:

Table 1: Preference of students

\begin{tabular}{cccc}
\hline Students & University “a” & University “b” & University "c" \\
\hline$s_{1}$ & $2^{\text {nd }}$ & $1^{\text {st }}$ & $3^{\text {rd }}$ \\
$s_{2}$ & $1^{\text {st }}$ & $2^{\text {nd }}$ & $3^{\text {rd }}$ \\
$s_{3}$ & $1^{\text {st }}$ & $2^{\text {nd }}$ & $3^{\text {rd }}$ \\
\hline
\end{tabular}

Table 2: Preference of universities

\begin{tabular}{cccc}
\hline University & Student 1 & Student 2 & Student 3 \\
\hline$U_{a}$ & $1^{\text {st }}$ & $3^{\text {rd }}$ & $2^{\text {nd }}$ \\
$U_{b}$ & $2^{\text {nd }}$ & $1^{\text {st }}$ & $3^{\text {rd }}$ \\
$U_{c}$ & $2^{\text {nd }}$ & $1^{\text {st }}$ & $3^{\text {rd }}$ \\
\hline
\end{tabular}

The preference of the students is shown in Table 1 and the preference of the universities is shown in Table 2. From the candidates' perspective, student 1 put the highest priority on university "b" as it gives them the highest payoff if they are selected by university " $b$ ", followed by university "a" and university "c". From the universities' perspective, university "a" puts the highest priority on student 1 , followed by student 3 and student 2 , meanwhile both university "b" and university "c" put the highest priority on student 2 , followed by student 1 and student 3 . Since each university can accommodate one student only, six different matchings can be formed by assuming each student can only submit one university choice as follows: 


$$
\begin{aligned}
& \mu_{1}=\left(\begin{array}{lll}
s_{1} & s_{2} & s_{3} \\
U_{a} & U_{b} & U_{c}
\end{array}\right), \mu_{2}=\left(\begin{array}{ccc}
s_{1} & s_{2} & s_{3} \\
U_{a} & U_{c} & U_{b}
\end{array}\right), \mu_{3}=\left(\begin{array}{ccc}
s_{1} & s_{2} & s_{3} \\
U_{b} & U_{a} & U_{c}
\end{array}\right) \\
& \mu_{4}=\left(\begin{array}{lll}
\mathrm{s} 1 & \mathrm{~s} 2 & \mathrm{~s} 3 \\
U_{a} & U_{b} & U_{c}
\end{array}\right) \mu_{-} 5=\left(\begin{array}{lll}
s_{1} & s_{2} & s_{3} \\
U_{c} & U_{a} & U_{b}
\end{array}\right), \mu_{3}=\left(\begin{array}{lll}
s_{1} & s_{2} & s_{3} \\
U_{c} & U_{b} & U_{a}
\end{array}\right)
\end{aligned}
$$

Matching $1\left(\mu_{1}\right)$ denotes that student 1 , student 2 and student 3 are assigned to university "a", university "b" and university "c" respectively and the same denotation applies to other matchings (i.e. $\mu_{2}$, etc.). In $\mu_{3}=\left(\begin{array}{ccc}s_{1} & s_{2} & s_{3} \\ U_{b} & U_{a} & U_{c}\end{array}\right)$, the matching is not stable because of student 3 and university " $a$ " form a blocking pair. The reason is that university "a" prefers student 3 over student 2 and student 3 prefers university "a" over university "c", but student 2 is paired with the university "a". The other unstable matchings are matchings $\mu_{4}$ and $\mu_{5}$. The welfare of the university and student is maximised in $\mu_{1}, \mu_{2}$ and $\mu_{6}$ because the matching has no blocking pair. In the present study, the number of blocking pairs reflects the degree of instability in the matching mechanism.

We form the hypotheses as below:

Hypothesis 1: In terms of the proportion of truth-telling, DAM should outperform IAM and ETM in both market sizes. This is because subjects in the experiment believe that DAM always promotes fairness in matching.

Hypothesis 2: Large market size (i.e. a higher number of students) should positively affect the proportion of truth-telling under all matching mechanisms. The reason is that the competition in the small market is stiffer than in the large market due to the limited number of seats available from all universities.

Hypothesis 3: In terms of stability, IAM should lose to DAM and ETM in both markets. DAM/ETM always fills up the capacity with students who score the highest and have ranked the university as their first choice followed by their second and third choice, then only proceed to match students who score lower until the capacity is exhausted. 
Hypothesis 4: The matching stability in the large market should be lower than the small market under the same matching mechanism. The formation of blocking pairs depends on the intensity of the competition. The less intense the competition, the higher the chance of forming a blocking pair.

\section{Experimental Design}

The experiment consisted of 6 sessions, with 3 different matching mechanisms x 2 different market sizes. The matching mechanisms were Immediate Acceptance Mechanism (IAM), Deferred Acceptance Mechanism (DAM) and Efficient Transfer Mechanism (ETM). Each mechanism was tested for its truth-telling and stability properties in two market sizes; small market size which had 30 subjects vying for 5 seats and large market size which had 30 subjects vying for 10 seats. The small market size should promote stiffer competition for seats among the subjects as there were only 5 seats available for 30 subjects compared to a large market with 10 seats for the same number of subjects. The design allowed comparing the effect of two market sizes and the performance of each mechanism. The experiment was programmed using experimental software (Fischbacher, 2007).

We recruited 360 undergraduate students who were from different faculties to be our subjects. Each student was allowed to participate in only one session to avoid learning effects. Each student was told to choose a university based on their most preferred to least preferred university. The preference of university among the subjects was reflected by the monetary payoff as shown in Table 3.

The payoff to the subject of different Universities was made significantly different to promote saliency between one's best choice and one's worst choice. For instance, the difference between the best choice and the worst choice for a student with 4.0 CGPA was RM30-RM20=RM10. The subjects' CGPA determined the university preference, for example, the student with 4.0 CGPA preferred University A as their first choice, but the student with 3.0 CGPA had University $\mathrm{C}$ as their first choice.

The requirement of preference of university on students was determined by capacity and CGPA level. Each university in the experiment had a different CGPA requirement and capacity. As shown in Table 4 above, University A sets minimum entry requirement at CGPA 4.0 and it has 2 seats and 1 seat available in a large market and small market respectively. 
Table 3: Preference of students according to CGPA

\begin{tabular}{lccc}
\hline \multicolumn{1}{c}{ Students' Payoff } & University A & University B & University C \\
\hline Student with 4.0 CGPA & RM 30 & RM 25 & RM 20 \\
Student with 3.9 CGPA & RM 30 & RM 25 & RM 20 \\
Student with 3.8 CGPA & RM 30 & RM 25 & RM 20 \\
Student with 3.7 CGPA & RM 30 & RM 25 & RM 20 \\
Student with 3.6 CGPA & RM 20 & RM 30 & RM 25 \\
Student with 3.5 CGPA & RM 20 & RM 30 & RM 25 \\
Student with 3.4 CGPA & RM 20 & RM 30 & RM 25 \\
Student with 3.3 CGPA & RM 20 & RM 30 & RM 25 \\
Student with 3.2 CGPA & RM 20 & RM 25 & RM 30 \\
Student with 3.1 CGPA & RM 20 & RM 25 & RM 30 \\
Student with 3.0 CGPA & RM 20 & RM 25 & RM 30 \\
\hline
\end{tabular}

Table 4: University entry requirement and its capacity

\begin{tabular}{|c|c|c|c|}
\hline \multirow[t]{2}{*}{ University } & \multirow{2}{*}{$\begin{array}{c}\text { Minimum Entry Point } \\
\text { (CGPA) }\end{array}$} & \multicolumn{2}{|c|}{ Capacity } \\
\hline & & Large Market & Small Market \\
\hline A & 4 & 2 & 1 \\
\hline $\mathrm{B}$ & 3.6 & 2 & 1 \\
\hline $\mathrm{C}$ & 3.3 & 6 & 3 \\
\hline
\end{tabular}

Upon entering the lab, the subjects were randomly assigned to a computer. The subjects were then given 10 minutes to read the instructions (See Appendix) before the experimenter began to explain the procedures in detail. The subjects were told of the CGPA, payoff they would receive if assigned a university and the requirement of each university, as shown in Figure 1 in the following.

From the figure, Box 1 indicates the CGPA that a student was assigned, in this case is 3.5 CGPA. Box 2 indicates the payoff that the subject would receive if assigned to University A is RM20, University B is RM30 and University C is RM25. Box 3 indicates the capacity available and CGPA required by each university. For example, University A has 2 seats and a minimum requirement is 3.7 CGPA. The experimenter then explained the allocation and selection mechanism used in each matching mechanism. The subjects were told that they were competing with other applicants and their final payoff depended on the final assignment. The assignment of 
Figure 1: Screenshot of what subjects saw during the experiment

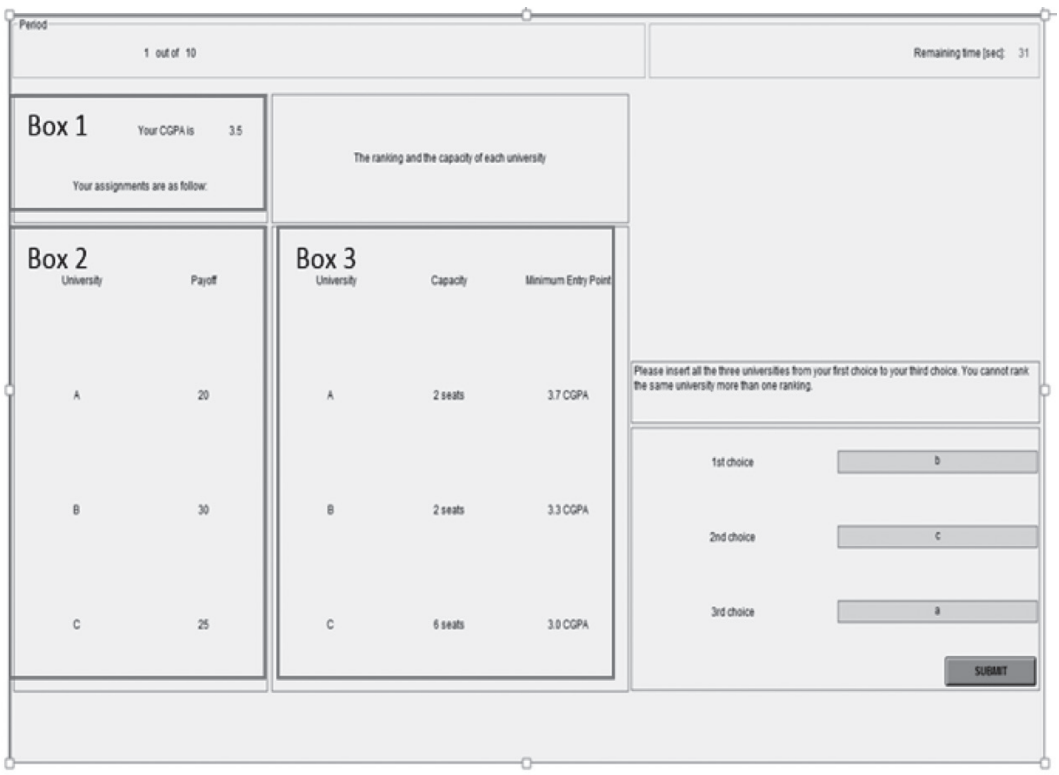

subjects' CGPA and payoff were changed randomly, therefore, subjects were faced with different decisions each round during the experiment (there were 10 rounds in total in the experiment).

After the briefing, the students were asked to submit the ranking of each university into the computer for ten rounds. The computer then displayed the university they were assigned to and the amount of payoff they received after each round. One out of 10 rounds was randomly chosen by the computer to be the subjects' final payoff. The subjects were paid immediately after the experiment. The average payoff for each subject was RM13. Each session lasted approximately 30 minutes.

\section{Experimental Results}

We use a logit model to investigate the effect of different matching mechanisms on the proportion of truth-telling and the number of blocking pairs (i.e stability). It is to compare the performance of each mechanism based on truth-telling and stability. The logit model takes the form of 
$\left(\begin{array}{c}P \\ 1-P\end{array}\right)=\beta_{1}+\beta_{2} D A M+\beta_{3} I A M+\varepsilon$. The variable DAM=1 when it is Deferred Acceptance Mechanism and IAM=0, IAM=1 when it is Immediate Acceptance Mechanism and $\mathrm{DAM}=0$ and $\beta_{1}$ is the constant, better known as the coefficient, for Efficient Transfer Mechanism. In truth-telling regression, the dependent variable, $P /(1-P)$ is the odd ratio with " 1 " denoting truthtelling and " 0 " denoting otherwise. In blocking pair regression, $P /(1-P)$ is the odd ratio that the matching has a blocking pair. In the binary outcomes, 1 denotes the blocking pair and 0 denotes otherwise.

Table 5: The proportion truth-telling and the blocking pair

\begin{tabular}{cccccc}
\hline \multicolumn{2}{c}{ The truth-telling } & \multicolumn{3}{c}{ The blocking pair } \\
\hline Coefficient & $\begin{array}{c}\text { Large } \\
\text { Market }\end{array}$ & $\begin{array}{c}\text { Small } \\
\text { Market }\end{array}$ & Coefficient & $\begin{array}{c}\text { Large } \\
\text { Market }\end{array}$ & $\begin{array}{c}\text { Small } \\
\text { Market }\end{array}$ \\
\hline constant & $0.18^{* *}$ & 0.06 & constant & $-4.18^{* * *}$ & $-6.39^{* * *}$ \\
& $(-3.80)$ & $(-0.73)$ & & $(-12.46)$ & $(-6.39)$ \\
DAM $=1,0$ & $0.380^{* * *}$ & 0.187 & DAM $=1,0$ & 0.107 & 0.694 \\
otherwise & -3.22 & -1.62 & otherwise & -0.23 & -0.57 \\
IAM =1, 0 & -0.107 & -0.013 & IAM $=1,0$ & 2.63 & $4.16^{* * *}$ \\
otherwise & $(-0.93)$ & $(-0.12)$ & otherwise & $(-7.47)$ & -4.12 \\
Log likelihood & - & - & Log likelihood & - & - \\
& 1222.1271 & 1242.6566 & & 375.82501 & 211.41825 \\
R2 & 0.0077 & 0.0015 & R2 & 0.1673 & 0.2064 \\
Observations & 1,800 & 1,800 & Observations & 1,800 & 1,800 \\
\hline
\end{tabular}

Notes: $* * *$ represents $1 \%$ significance level, $* *$ represents $5 \%$ significance level and $*$ represents $10 \%$ significance level. The parentheses are the $\mathrm{Z}$ statistics.

Table 5 reports the results of the logit regression with estimated coefficients and $\mathrm{Z}$ statistics in the parentheses for large and small markets. The overall results, the left column "The Truth-Telling", reveal that the log odd of truth-telling in DAM is larger than in ETM and IAM in both markets. The following analysis compares the probability of truth-telling and blocking pairs occurring in each market size. 
Table 6: Probability of truth-telling in each matching mechanism with respect to market size

\begin{tabular}{cccc}
\hline \multicolumn{2}{c}{ Large Market } & \multicolumn{2}{c}{ Small Market } \\
\hline IAM & 0.518 & IAM & 0.511 \\
DAM & 0.636 & DAM & 0.561 \\
ETM & 0.545 & ETM & 0.515 \\
\hline
\end{tabular}

Table 6 reports the probability of truth-telling for all matching mechanisms. The probability of telling the truth in the large market is higher than the small market. The probability of telling true preferences in the large market is 0.636 and the small market is 0.561 in DAM mechanism. However, the results show there is no significant difference between the large market and the small market in IAM treatment $(\mathrm{P}=0.2446)$, DAM treatment $(\mathrm{P}=0.5664)$ and $\mathrm{ETM}$ treatment $(\mathrm{P}=0.2980)$. The $\mathrm{K}$-Wallis test also shows the proportion of truth-telling in the large market is not significantly higher than in the small market in IAM treatment $(\mathrm{P}=0.9132)$, DAM treatment $(\mathrm{P}=0.6427)$ and $\mathrm{ETM}$ treatment $(\mathrm{P}=0.4703)$.

Comparing among mechanisms, the results show the probability of revealing true preferences in DAM treatment is statistically higher than ETM and IAM treatments in the large market $(\mathrm{P}=0.0000)$ and small market $(\mathrm{P}=0.0002)$. The statistical findings are consistent with the $\mathrm{K}$-Wallis test, in the large market $(\mathrm{P}=0.0001)$ and small market $(\mathrm{P}=0.0046)$.

The statistical results from the between market size comparison do not conform to hypothesis 2 but the statistical results from among matching mechanisms comparison conform to hypothesis 1. Using the DAM mechanism is far more effective in encouraging students to report their true most preferred university than ETM and IAM mechanisms in both small and large markets.

\subsection{Evolution of truth-telling}

During the experiment, each session required subjects to make decisions from round one to round ten. This allows us to check if the truth-telling is a random decision based on the consistency of the choices throughout the ten periods. If the decision of telling the truth is not random, the average proportion of truth-telling between $1^{\text {st }}$ interval (from round 1 to round 5) and $2^{\text {nd }}$ interval (from round 6 to round 10 ) should not be significantly different. 
Figure 2: Evolution of truth-telling from round 1 to round 10 in the large market (left panel) and small market (right panel)
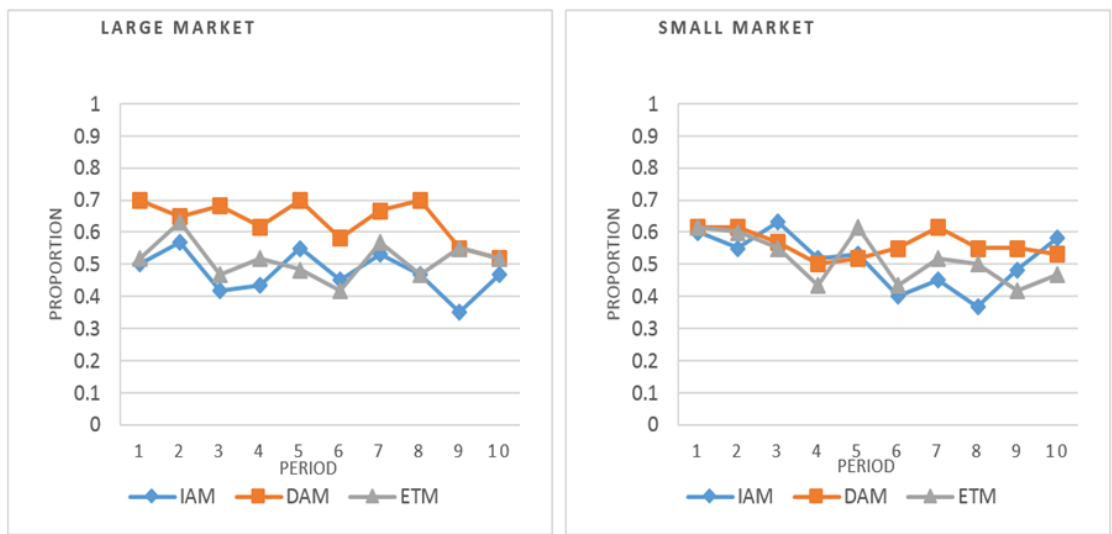

Figure 2 shows the proportion of truth-telling from round one to round ten. The average of truth-telling in the first interval is not significantly different from the second interval in IAM treatment in $(\mathrm{P}=0.2249)$, DAM treatment $(\mathrm{P}=0.1391)$ and ETM treatment $(\mathrm{P}=0.3739)$ in the large market. In the small market, the average proportion of truth-telling in the $1^{\text {st }}$ interval is significantly higher than in the $2^{\text {nd }}$ interval in ETM treatment $(\mathrm{P}=0.0360)$. However, there is no significant difference between the 1st and 2nd interval in DAM treatment $(\mathrm{P}=0.8613)$ and IAM treatment $(\mathrm{P}=0.1235)$.

\subsection{Matching stability}

The logit model takes the form of $\ln \left(\begin{array}{c}P \\ 1-P\end{array}\right)=\beta_{1}+\beta_{2} D A M+\beta_{3} I A M+\varepsilon$ with dummy variables DAM=1 when it is Deferred Acceptance Mechanism and $\mathrm{IAM}=0, \mathrm{IAM}=1$ when it is Immediate Acceptance Mechanism and $\mathrm{DAM}=0$ and $\beta_{1}$ is the constant or better known as the coefficient for Efficient Transfer Mechanism. The dependent variable, $P /(1-P)$ is the odd ratio that the matching has a blocking pair. In the binary outcomes, 1 denotes blocking pairs and 0 denotes otherwise.

Table 5 right column "The blocking pair", reports the results of the logit analysis with estimated coefficients and $\mathrm{Z}$ statistics in the parentheses for large and small markets. The results reveal that the log odd of blocking pairs in IAM is higher than ETM and DAM in both markets. The probability of blocking pairs is shown in the following table: 
Table 7: Probability of blocking pars in each matching mechanism and each market size

\begin{tabular}{cccc}
\hline \multicolumn{2}{c}{ Large Market } & \multicolumn{2}{c}{ Small Market } \\
\hline IAM & 0.15 & IAM & 0.085 \\
DAM & 0.015 & DAM & 0.011 \\
ETM & 0.015 & ETM & 0.008 \\
\hline
\end{tabular}

The probability of forming a blocking pair in the large market is statistically higher than in the small market for all matching treatments. However, the statistical results show that there is no significant difference between the large market and the small market in DAM treatment $(\mathrm{P}=0.6158)$ and $\mathrm{ETM}$ treatment $(\mathrm{P}=0.2893)$. On the contrary, the probability of forming a blocking pair in the large market is significantly higher than the small market in IAM treatment $(\mathrm{P}=0.0006)$. The statistical findings are consistent with the K-Wallis test. The number of blocking pairs in the large market is significantly higher than in the small market in IAM treatment $(\mathrm{P}=0.0001)$, but there is no significant difference between large market and small market in DAM treatment $(\mathrm{P}=0.7565)$ and ETM treatment $(\mathrm{P}=0.4423)$.

The results also show that the probability of blocking pairs occurring in IAM treatment is statistically higher than in ETM treatment and DAM treatment in the large market $(\mathrm{P}=0.0000)$ and small market $(\mathrm{P}=0.0000)$. The $\mathrm{K}$-Wallis test also shows that the number of blocking pairs in IAM treatment is significantly higher than the other two treatments in the large market $(\mathrm{P}=0.0001)$ and small market $(\mathrm{P}=0.0001)$.

The statistical results from a between market size comparison in IAM mechanism conforms to hypothesis 4 and among matching mechanisms comparison in both markets and hypothesis 3 . In short, the large market size has a negative impact on matching stability as the number of blocking pairs is significantly larger as compared to small market size in IAM mechanism. The matching in IAM mechanism is less stable than ETM and DAM mechanisms in both markets.

\subsection{Evolution of blocking pairs}

This section checks the consistency of the matching mechanisms under study. If the matching stability under a mechanism is consistently formed, 
the total formation of blocking pairs between $1^{\text {st }}$ interval (from round 1 to round 5) and $2^{\text {nd }}$ interval (from round 6 to round 10) should be indifferent.

Figure 3: Evolution of blocking pairs from round 1 to round 10 in large market (left panel) and small market (right panel)
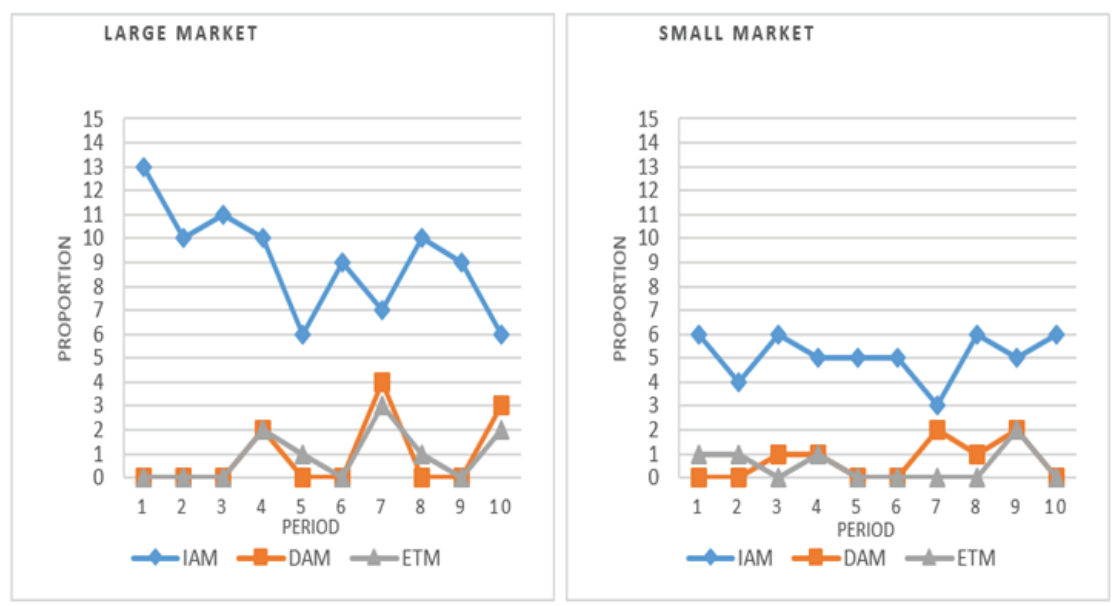

Figure 3 shows the proportion of blocking pairs from round one to round ten. The average of blocking pairs in the first interval is not significantly different from the second interval in DAM treatment $(\mathrm{P}=0.1599)$ and IAM treatment $(\mathrm{P}=0.5637)$ and ETM treatment $(\mathrm{P}=0.3961)$ in the large market. On the contrary, the number of blocking pairs in the first interval is significantly higher than in the second interval in IAM treatment $(\mathrm{P}=0.0556)$.

In the small market, the average of blocking pairs, the first interval is not significantly different from the second interval in IAM treatment $(\mathrm{P}=0.5637)$, DAM treatment $(\mathrm{P}=0.1599)$ and $\mathrm{ETM}$ treatment $(\mathrm{P}=0.5637)$. In conclusion, the stability of DAM and ETM treatments is consistent across 10 rounds under medium informational setup in large and small markets.

\subsection{The correlation between truth-telling and blocking pairs}

A correlation test allows one to investigate the association between truthtelling and the number of blocking pairs. From Table 8 , it is apparent that a high proportion of truth-telling is associated with a low number of blocking pairs except in the IAM matching mechanism. 
Table 8: The correlation between truth-telling and the number of blocking pairs

\begin{tabular}{ccc}
\hline Matching Mechanism & LM & SM \\
\hline DAM & $-0.3981^{*}$ & 0.2273 \\
ETM & $-0.4177^{*}$ & -0.3308 \\
IAM & $0.4247^{*}$ & 0.3557 \\
\hline
\end{tabular}

Notes: *represents the correlation is below $10 \%$ significance. LM indicates large market that has 30 subjects and 10 seats available, SM indicates small market that has 30 subjects and 5 seats available.

The stability of a mechanism reflects the welfare of both students and university; students get the university they aspire and the university gets its talents. Telling the truth about one's preferred University is the dominant strategy in both DAM and ETM but not in the IAM mechanism. This is reflected by the correlation; telling the truth enhances welfare in DAM and ETM but not in IAM.

\section{Discussions and Conclusions}

In this paper, we analysed three common matching mechanisms - the IAM, DAM and ETM in allocating seats to students with different academic results - under two different market sizes. The large market size has 30 subjects and 10 seats available and the small market size has 30 subjects and 5 seats available. Our experimental design allows us to analyse three main questions. Firstly, we compare the three mechanisms in terms of truth-telling and the welfare of university and students (a.k.a. matching stability) in two different market settings. Secondly, we evaluate the effect of market size on subjects' truth-telling behaviour and matching stability in each matching mechanism. Thirdly, we check the relationship between truth-telling by the students and the welfare of both parties under each matching mechanism.

Although the three matching mechanisms have been widely studied in past papers (Chen et al., 2018; Chen \& Kesten, 2017; Pais et al., 2011), the truth-telling and stability properties of each matching mechanism have not been investigated in different market sizes. This is important as most of the problems, such as misreporting of preferences, misallocation of resources, "exploding offers" and others occurred when the market is congested with more offers than it can handle (i.e. small market size in the present paper) (Roth, 2015). 
In choosing the right candidate, a selection process looks into the qualifications and also the interest of the students to attend the course if chosen. The selection process admits the candidates as long as they are qualified and rank the university high in the application form. In the Immediate Acceptance Mechanism, these candidates are immediately offered a place as they have shown their interest by ranking the university very high in their preference list. Those candidates who rank the university/course low in the preference list will not be considered as they do not show their interest. The process creates incentives to misreport their true preferences; in a very competitive race to enter a prestigious university/course due to too many applications, candidates who are qualified may rank the second or third best university/course as their first choice and their first best university/ course as their second or lower choice because of fearing of losing the race. The present paper begins with the intention to test the extent of misreporting of true preferences and the number of misallocations in three different matching mechanisms, the performance of these mechanisms in different market sizes and how misreporting can be associated with misallocation.

Truthful preference revelation among students is essential to pair the most suitable and qualified candidates with the university. Our results are consistent with the experimental findings that show the proportion of truth-telling is highest under the DAM mechanism than the other matching mechanisms (Chen et al., 2018; Chen \& Kesten, 2017; Pais et al., 2011). When we dwelt further on the truth-telling property of each mechanism based on market size, we find that the proportion of truth-telling in the large market is higher than in the small market for all matching mechanisms. The results confirm that market size has an impact on subjects' misreporting tendency (Chen et al., 2018; Fudenberg, Mobius \& Szeidl, 2007). In the large market, the chance for a subject to match with a university is higher than in the small market due to the larger number of seats available that subjects can choose. Therefore, when the competition grows stiffer in the small market due to the limited number of seats, subjects become more likely to misrepresent their true preference. This implies that subjects are willing to trade the lower chance of getting their top choices with a higher chance of getting their unfavorable choices when the market is faced with a shortage of seats.

When comparing the matching stability among different mechanisms, our results show that IAM is less stable than DAM and ETM in both 
markets. The result is consistent with the theoretical findings in Dubins and Freedman (1981); Gale and Shapley (1962); Roth and Sotomayor (1992). Adopting DAM and ETM mechanisms assures that the university gets its most qualified students and students get their most aspired university, in other words, the welfare of both parties is maximixed under both mechanisms.

The effect of market sizes on stability on a matching mechanism is mixed as reported in the literature. On the one hand, Chen et al. (2018) shows that increasing the number of applicants had no significant impact on matching stability, on the other hand, research by Dickerson, Procaccia and Sandholm (2012) shows that the number of compatible matching rose significantly as the size of the donor pool increased relative to the number of patients. When we look into the effect of market size on stability, we find that offering a small number of seats positively affects the stability of a matching mechanism. This is the new insight that allows the present study to contribute to the past findings. The selection process in the small market becomes fairer when a pool of subjects ranks their non-favourable university as their most preferred university in the application form. For illustration purposes, there are 3 students with 4.0 CGPA and 4 students with 3.9 CGPA in the market and each university has only 1 seat. The true preference of students with 4.0 CGPA and 3.9 CGPA is A-B-C. All of them manipulate their preferences and submit C-B-A due to the limited number of seats. As a result, students with 4.0 CGPA are assigned to University C, University B or University A and none of the students with 3.9 CGPA is given a seat. Thus, the matching outcome has no blocking pairs and it is stable.

Lastly, our results show that telling the truth decreases the number of blocking pairs in DAM and ETM as compared to IAM in both markets. In a fair evaluation process, the chance for subjects to get their aspired university/ course and for a university/course to recruit their aspired talents is low if they misrepresent their true preference. However, misallocation of seats to students happens in IAM even if subjects reveal their true preference because the selection process gives higher priority to subjects who rank the university as their top choice, instead of their qualification. The present study confirms that revealing true preference is the dominant strategy in both DAM and ETM as the welfare of university and student is improved from the high proportion of truth-telling among subjects. 


\section{Acknowledgement}

The research is financed by Research University (RU) grant with account number 1001/PSOSIAL/8016067.

\section{References}

Abdulkadiroğlu, A., Che, Y.-K. \& Yasuda, Y. (2011). Resolving conflicting preferences in school choice: The "Boston mechanism" reconsidered. American Economic Review, 101(1), 399-410.

Abdulkadiroglu, A., Pathak, P., Roth, A. E. \& Sonmez, T. (2006). Changing the Boston school choice mechanism. National Bureau of Economic Research. Retrieved from https://www.nber.org/papers/w11965.pdf.

Abdulkadiroglu, A. \& Sönmez, T. (2003). School choice: A mechanism design approach. American Economic Review, 93(3), 729-747. doi: $10.1257 / 000282803322157061$

Abdulkadiroğlu, A. \& Sönmez, T. (1999). House allocation with existing tenants. Journal of Economic Theory, 88(2), 233-260. doi.org/10.1006/ jeth.1999.2553

Abdulkadiroğlu, A. \& Sönmez, T. (2003). School choice: A mechanism design approach. American Economic Review, 93(3), 729-747. doi:10.1257/000282803322157061

Alcalde, J. \& Barberà, S. (1994). Top dominance and the possibility of strategy-proof stable solutions to matching problems. Economic Theory, 4(3), 417-435. doi.org/10.1007/BF01215380

Azevedo, E. M. \& Budish, E. (2018). Strategy-proofness in the large. The Review of Economic Studies, 86(1), 81-116. doi.org/10.1093/restud/ rdy042

Azevedo, E. M. \& Leshno, J. D. (2016). A supply and demand framework for two-sided matching markets. Journal of Political Economy, 124(5), 1235-1268. doi.org/10.1086/687476

Balinski, M. \& Sönmez, T. (1999). A tale of two mechanisms: student placement. Journal of Economic Theory, 84(1), 73-94. doi.org/10.1006/ jeth.1998.2469

Bodine-Baron, E., Lee, C., Chong, A., Hassibi, B. \& Wierman, A. (2011). Peer effects and stability in matching markets. In International Symposium on Algorithmic Game Theory, (pp. 117-129). Berlin, 
Heidelberg: Springer, 2011. doi: 10.1007/978-3-642-24829-0_12

Calsamiglia, C., Haeringer, G. \& Klijn, F. (2010). Constrained school choice:

An experimental study. American Economic Review, 100(4), 1860-1874. doi: 10.1257/aer.100.4.1860

Chen, Y., Jiang, M., Kesten, O., Robin, S. \& Zhu, M. (2018). Matching in the large: An experimental study. Games and Economic Behavior, 110, 295-317. doi.org/10.1016/j.geb.2018.04.004

Chen, Y. \& Kesten, O. (2017). Chinese college admissions and school choice reforms: A theoretical analysis. Journal of Political Economy, 125(1), 99-139. doi.org/10.1086/689773

Coase, R. (1960). The problem of social cost. Journal of Law and Economics, 3, 1-44.

Coles, P., Cawley, J., Levine, P. B., Niederle, M., Roth, A. E. \& Siegfried, J. J. (2010). The job market for new economists: A market design perspective. Journal of Economic Perspectives, 24(4), 187-206. doi: 10.1257/jep.24.4.187

Dickerson, J. P., Procaccia, A. D. \& Sandholm, T. (2012). Optimizing kidney exchange with transplant chains: Theory and reality. Paper presented at the Proceedings of the $11^{\text {th }}$ International Conference on Autonomous Agents and Multiagent Systems-Volume 2. (pp. 711-718). 2012. Retrieved from http://www.cs.cmu.edu/ sandholm/www/chains. aamas12.pdf

Dubins, L. E. \& Freedman, D. A. (1981). Machiavelli and the Gale-Shapley algorithm. The American Mathematical Monthly, 88(7), 485-494. doi.or $\mathrm{g} / 10.1080 / 00029890.1981 .11995301$

Ergin, H. \& Sönmez, T. (2006). Games of school choice under the Boston mechanism. Journal of Public Economics, 90(1-2), 215-237. doi. org/10.1016/j.jpubeco.2005.02.002

Fischbacher, U. (2007). z-Tree: Zurich toolbox for ready-made economic experiments. Experimental Economics, 10(2), 171-178. doi.org/10.1007/ s10683-006-9159-4

Fudenberg, D., Mobius, M. \& Szeidl, A. (2007). Existence of equilibrium in large double auctions. Journal of Economic Theory, 133(1),550-567. doi.org/10.1016/j.jet.2005.07.014

Gale, D. \& Shapley, L. S. (1962). College admissions and the stability of marriage. The American Mathematical Monthly, 69(1), 9-15. doi.org/10 $.1080 / 00029890.1962 .11989827$ 
Haeringer, G. \& Klijn, F. (2009). Constrained school choice. Journal of Economic Theory, 144(5), 1921-1947. doi.org/10.1016/j.jet.2009.05.002

Hakimov, R. \& Kübler, D. (2019). Experiments on matching markets: $A$ survey. WZB Discussion Paper, No. SP II 2019-205. Retrieved from https://www.econstor.eu/bitstream/10419/196908/1/1665818794.pdf.

Immorlica, N. \& Mahdian, M. (2005). Marriage, honesty and stability. Paper presented at the Proceedings of the Sixteenth Annual ACM-SIAM Symposium on Discrete Algorithms.

Kojima, F. \& Pathak, P. A. (2009). Incentives and stability in large two-sided matching markets. American Economic Review, 99(3), 608-627. doi: 10.1257/aer.99.3.608

Kojima, F. \& Unver, M. U. (2010). The 'Boston'school choice mechanism. Documento de Trabajo, Boston College, febrero. Retrieved from https:// www.cemfi.es/ftp/pdf/papers/wshop/School\%20choice.pdf

McKinney, C. N., Niederle, M. \& Roth, A. E. (2005). The collapse of a medical labor clearinghouse (and why such failures are rare). American Economic Review, 95(3), 878-889. doi: 10.1257/0002828054201323

Miralles, A. (2009). School choice: The case for the Boston mechanism. In International conference on auctions, market mechanisms and their applications, pp. 58-60. Berlin, Heidelberg: Springer, doi. org/10.1007/978-3-642-03821-1_9

Pais, J., Pintér, Á. \& Veszteg, R. F. (2011). College admissions and the role of information: An experimental study. International Economic Review, 52(3), (pp. 58-60). doi.org/10.1111/j.1468-2354.2011.00647.x

Pathak, P. A. (2011). The mechanism design approach to student assignment. Annual Review of Economics, 3(1), 513-536. doi.org/10.1146/annureveconomics-061109-080213

Roth, A. E. (1982a). The economics of matching: Stability and incentives. Mathematics of Operations Research, 7(4), 617-628. doi.org/10.1287/ moor.7.4.617

Roth, A. E. (1982b). Incentive compatibility in a market with indivisible goods. Economics Letters, 9(2), 127-132. doi.org/10.1016/01651765(82)90003-9

Roth, A. E. (2015). Who Gets What-and Why: The New Economics of Matchmaking and Market Design. Houghton Mifflin Harcourt.

Roth, A. E. \& Sönmez, T. (2005). A kidney exchange clearinghouse in New England. American Economic Review, 95(2), 376-380. doi: 
$10.1257 / 000282805774669989$

Roth, A. E. \& Sotomayor, M. (1992). Two-sided matching. Handbook of Game Theory with Economic Applications, 1, 485-541.

Troyan, P. (2012). Comparing school choice mechanisms by interim and ex-ante welfare. Games and Economic Behavior, 75(2), 936-947. doi. org/10.1016/j.geb.2012.01.007

Willian, J. \& Milgrom, R. (2005). Matching with contracts. American Economic Review, 95(4), 913-935. doi: 10.1257/0002828054825466

\section{Appendix}

\section{General Instruction for All Matching Treatment}

Welcome to the experiment, during the experiment, you are required to make some decisions and perform some tasks. You will be paid and the amount depends on your decision during the experiment. In the experiment, you will be playing a role as student who is applying for a course/place in a public university.

The requirement to enter university, which is your CGPA from STPM or A-level or Matriculation, is varied from CGPA 3.0 to CGPA 4.0. During the experiment, you will be assigned a CGPA.

Please abide by the following rules to ensure the experiments run in optimal conditions.

- You are not allowed to communicate with other participants during the experiment.

- You are required to switch off your mobile phone.

- If you have any questions, feel free to ask before the experiment.

\section{The Task}

The task requires you to choose which University you prefer for 10 rounds. There are 30 students with different CGPAs applying for a place offered by 3 different universities with different entry requirements and capacity. After you have submitted your choice in each round, a mechanism will determine which University you are matched to. We will explain how the mechanism works in the following section. 


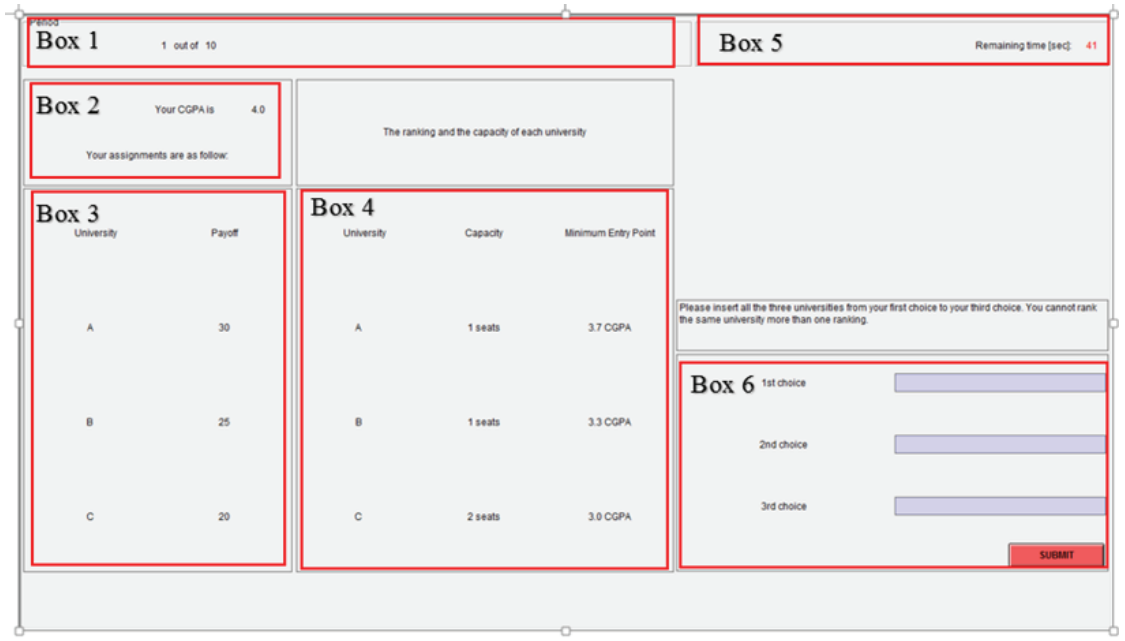

1. Box 1 shows you are now in round 1 and there are 9 more rounds left.

2. Box 2 shows your CGPA is 4.0 .

3. Box 3 shows the payoff that you will receive if matched with a university. E.g. if you are matched with University A, you will be paid RM30 and RM25 if University B and RM20 if University C.

4. Box 4 shows the minimum entry point and the capacity of each university. University A only accepts 1 student who score 3.7 CGPA and above, University B only accepts 1 students who score 3.3 CGPA and above, University $\mathrm{C}$ only accepts 2 students who score 3.0 CGPA and above.

5. Box 5 shows the time left (41 seconds) for you to submit your choice in this round.

6. Box 6 requires you to fill in your choices. E.g. If you prefer University A as your first choice, University B as second choice, University $\mathrm{C}$ as third choice. Then, you have to enter " $\mathrm{A}$ " in the first blue box, enter "B" in the second blue box and enter " $\mathrm{C}$ " in the third blue box. Click the "SUBMIT" button to proceed to result screen.

The result screen will then display your submitted ranking and payoff in round 1 . The figure below shows the example of the new screen. 


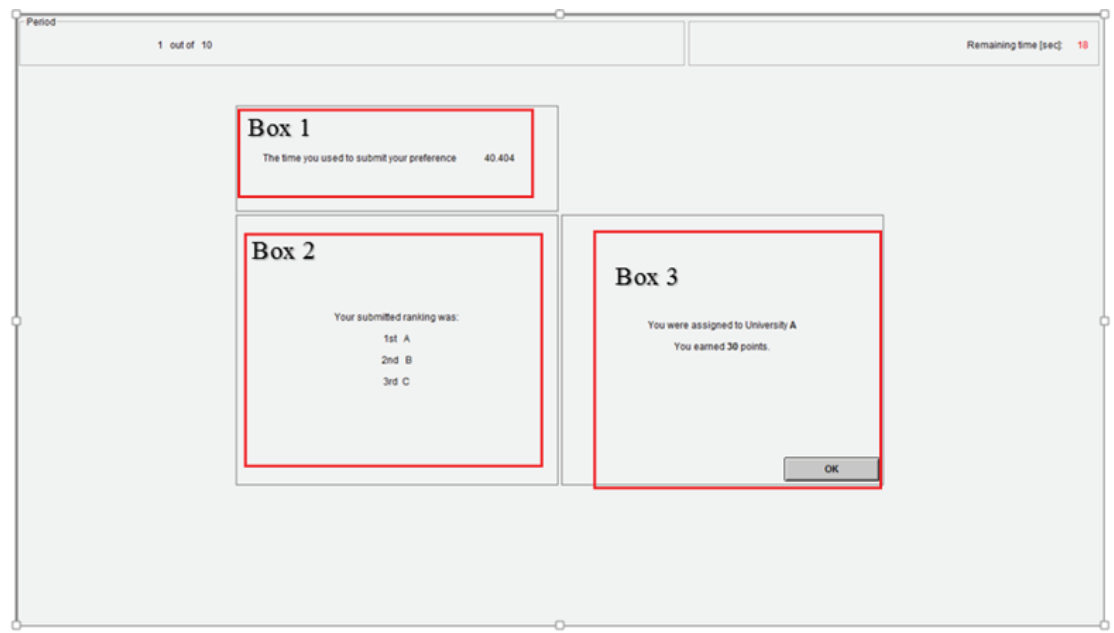

1. Box 1 shows you used 40.404 seconds to complete the task in round 1. (Time spent in each round to make decision is used to break tie and subjects with the shortest time spent should be given priority.)

2. Box 1 shows your $1^{\text {st }}$ preference in round 1 was University $B, 2$ nd preference was University $\mathrm{C}$ and 3rd ranking was University A.

3. Box 2 shows you were matched with University A and earned RM30 in round 1. Press the "OK" button to proceed to round 2.

The figure below shows an example when you are asked to submit your preference in round 2 .

\begin{tabular}{|c|c|c|c|c|c|c|}
\hline Box 1 & 2 areat 10 & & & & Box 5 & 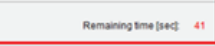 \\
\hline Box 2 & rearccents 36 & & & & 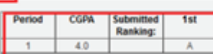 & 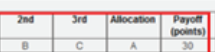 \\
\hline & 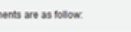 & & & & Box 6 & \\
\hline Box 3 & Pand & Box 4 & coment & on forpont & & \\
\hline A & 20 & $\hat{A}$ & 1000 & 370000 & 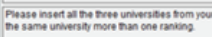 & 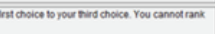 \\
\hline & & & & & Box 7 traseces & \\
\hline - & ж0 & - & soses & $33000 \times$ & ansomese & \\
\hline c & 25 & c & 2 & socoen & mosomeace & \\
\hline
\end{tabular}


The result screen will then display your matching and payoff in round 2. Press the "OK" button to proceed to round 3. In total you need to make 10 similar decisions in 10 rounds. One out of 10 rounds will be randomly chosen to be your final payoff. It means each round is equally important. 
